\title{
Focusing on Health to Advance Sustainable Urban Transitions
}

Yonette F. Thomas, Jo Ivey Boufford, and Shamin Hayder Talukder

Rapid regional and global changes are transforming living spaces and lifestyles, demographic trends, and the global environment, all with important consequences for human health and wellbeing. Urbanization is of primary importance among the forces affecting population health. A significant percentage of the global population lives within cities and the proportion of urban dwellers is rapidly increasing. According to World Health Organization (WHO) Global Health Observatory (GHO), population experts have estimated that by $2050,70 \%$ of the world's population will be urban dwellers and most of this increase is taking place in lowand middle-income countries.

Attention to cities has grown more visible worldwide with the recent adoption by the United Nations of the first-ever urban goal (Goal 11) among the 17 Sustainable Development Goals (SDGs) and the creation of the "New Urban Agenda" as planning continues for the Habitat III Conference in Quito, Ecuador in October of 2016. Both of these agreements will shape regional and national plans of all countries for future urban social and economic development, and the International Society for Urban Health (ISUH) is committed to assuring that strategies that advance "urban health" are priorities in all such plans.

Established in 2001 at the New York Academy of Medicine, its aim is the networking of scientists from different disciplines (e.g., social sciences, public health, urban planning, and policy sciences), practitioners from multiple sectors, and persons from civil society around the world whose work is directly related to the broad determinants of health in urban environments and the process of urbanization. Its goal is to facilitate the development of an evidence base for urban policy and practice that promotes a healthy environment and healthy population. One of its core activities is an annual International Conference on Urban Health which has become a platform for critical thinking to advance innovative action on urban health.

ICUH conferences provide an international forum for gathering experts in urban health across disciplines and geographic boundaries to exchange ideas and advance research and practice that promote the health of individuals in cities, especially focusing on communities experiencing the greatest burden of disease and health disparities. The ultimate goal of each conference is to build networks among individuals engaged in urban health research, planning, and implementation, and to promote the greater understanding of the importance of urban health.

Thomas is with the The New York Academy of Medicine and the Association of American Geographers, New York, NY, USA; Boufford is with the The New York Academy of Medicine, New York, NY, USA; Talukder is with the Eminence Associates for Social Development, Dhaka, Bangladesh.

Correspondence: Yonette F. Thomas, The New York Academy of Medicine and the Association of American Geographers, New York, NY, USA. (E-mail: CMoore@nyam.org) 
Reflecting the opportunity to influence development of the UN SDGs, the 2015 ICUH held in Dhaka, Bangladesh (May 24-27), was dedicated to the theme of exploring the importance of urban health to sustainable development and resulted in a call to action encapsulated as the Dhaka Statement on Urban Health in Sustainable Development. The conference was hosted by Eminence Associates for Social Development (www.eminence-bd.org), a Bangladeshi nongovernmental organization, and the Bangladesh Urban Health Network (BUHN) and jointly organized and supported by the New York Academy of Medicine, as the ISUH secretariat. Supporting partners within the Government of the People's Republic of Bangladesh included the Ministry of Local Government, Rural Development, and Cooperatives and the Ministry of Health and Family Welfare. International supporting partners included the Bill and Melinda Gates Foundation, the United States Agency for International Development (USAID), the Swedish International Development Cooperation Agency (SIDA), Asian Development Bank (ADB), The Kingdom of the Netherlands, WaterAid Bangladesh, Save the Children, and others. Over 1000 delegates from Bangladesh, South Asia, and approximately 60 countries around the world participated in the conference. Over 300 scientific papers were presented along with plenary talks given by leaders in urban health on four overarching themes: (1) socioeconomic and environmental determinants of urban health and health inequities; (2) urban health care and public health service provision across the life course; (3) measuring, mapping, and monitoring urban health; and (4) strengthening governance for urban health. Plenaries reflected these themes as a means of generating recommendations for action from each. The topics included the following: (1) Community based Prevention of NCDs, Injury and Communicable Diseases; (2) Built and Natural Environmental Determinants of Health; (3) Actions on the Social Determinants; (4) Urban Health Care Services Provisions; (5) Measuring, Mapping and Monitoring Urban Health; (6) Governance for Urban Health; and (7) The post 2015 Sustainable Development: issues of urban health.

Five special sessions held by local Bangladeshi organizations and their local and international sponsors showcased urban health studies and implementation projects, and the Bill and Melinda Gates Foundation supported a special reproductive and family planning track. The track focused on the unique challenges of education and service provision for reproductive, maternal, neonatal, and child health $(\mathrm{RMNCH})$ in the urban environment, especially for poor women living in urban slums.

An important outcome of the conference was the adoption of the Dhaka Statement. The Statement was endorsed by participants and local policy makers as a roadmap for achieving urban health as global, regional, national, and local action plans are developed in response to the sustainable development goals and as a call to action to recognize urban health as a priority in sustainable development.

The key elements of the Dhaka Statement focused on cities as the main drivers of national development and offer access to a wide array of goods and services including health, education, and social and cultural opportunities. Specifically,

- People are attracted to live in urban areas because of the potential to improve their lives, including through economic opportunities. As a result, urban residents often provide important economic support to their rural home communities.

- When urban growth is effectively managed, cities can be part of the solution to sustainable national development. 
- If plans for the built environment (e.g., housing, land use, transport) include consideration of health impact, cities can facilitate healthy choices of food, exercise, and social engagement, as well as maximize resilience of its residents.

- If well managed, cities can be engines of development for national economies, hubs for technological innovation, and centers of positive social progress including advancing the education and empowerment of women and child survival and development.

- Population density in cities can facilitate delivery of development interventions to large numbers of people.

Cities can also be sites of extreme poverty, environmental degradation, inadequate infrastructure, and a combination of risk factors that have adverse effects on health. Consequently,

- Countries that fail to plan for increasing urbanization place their citizens at serious health, economic, and security risk.

- The health of slum dwellers and the homeless is typically well below that in other urban and rural areas, even when stratified by poverty level. These inequities are also observed in other critical development indicators that affect the health of all residents.

- In addition to traditional urban health challenges of water, sanitation, infectious diseases, and environmental pollutants, city residents confront chronic diseases linked to poor diets, sedentary lifestyles, and obesity. Urban dwellers also face physical and mental health issues linked to safety, violence, poverty, and unemployment, and they are at risk for road accidents and other injuries.

- Coastal cities face particular risk from the effects of climate change, including extreme weather events, natural disasters, sea level rise, and floods.

- Settlements without legal status, basic infrastructure, energy security, and services can become loci of social tension, conflict, and illicit economic activity.

Strong and effective governance is required to promote urban health with clear roles for city and local government and a strong public health infrastructure that can work in partnership with other sectors to prevent and mitigate potential risks and benefits to the health of policies, programs, and investments across sectors (a Health-In-All approach).

The Statement acknowledges key reports and initiatives that highlight the growing importance of cities in achieving sustainable development, and recognizes that the health of people living in cities is affected by multiple factors, that decisions in all sectors can have positive or negative effects on human health, and that healthy people are critical to social and economic development (Footnote these).

Nine key action items are articulated in the Statement and will continue to be advanced and monitored by the ISUH as both the SDGs and Habitat plans are developed and implemented at Country level. These include:

1. Specific reference to the critical importance of the health of urban dwellers to achieving the Sustainable Development Goals in the planned political declaration that will preface the goals

2. Mainstreaming consideration of the unique opportunities and challenges of urban environments across the SDGs

3. Recognition of the pressing need for evidence-based and cost-effective interventions that address the effects of urban diversity, complexity, density, 
and disparities on the social and structural determinants of health in order to achieve the health targets outlined in SDG Goal 3: Ensure healthy lives and promote well-being for all at all ages

4. Inclusion of a commitment that the solutions chosen have a positive impact on human health and do not adversely affect health of people in cities, in the targets for SDG Goal 11: Make cities and human settlements inclusive, safe, resilient, and sustainable

5. Development of national-level health policy that integrates planning for rural and urban areas and recognizes the importance of city- and local-level data and action to advance urban health.

6. Inclusion of targets and indicators to implement SDGs at the national level that reflect progress towards urban health and health equity;

7. Incorporation of key tools to advance the health of people in cities, including resource mobilization for capacity building, applied research, and strengthening governance for urban health, in the outcome documents of the Third International Conference on Financing for Development (2015), The United Nations Climate Change Conference (2015), and Habitat III (2016)

8. Incorporation of expertise from the global professional and academic health communities in seeking to define, understand, and address the major challenges of global urban development into the intergovernmental process leading up to the United Nations Conference on Housing and Sustainable Urban Development (Habitat III), to take place in Quito, Ecuador in October 2016

9. Acknowledgment of the role of health as both input for and outcome of development, particularly the broad interplay between urban design, planning and management, and urban health and health equity, in the New Urban Agenda that will emerge from Habitat III.

We invite you to join us in this effort to assure that urbanization can be a positive influence for global health.

Footnote: These include:

- The Synthesis Report of the UN Secretary General on the Post 2015 Agenda (2014), which identifies six essential elements for delivering the SDGs and proposes 17 Sustainable Development Goals, including a specific goal for health (\#3) and for cities $(\# 11)$

- The WHO's Joint Statement of the UN Platform on Social Determinants of Health (WHO) which outlines the relationship between health and other societal goals across multiple sectors: the economy and employment; security and justice; education and early life; agriculture and food; architecture, planning, and transportation; environment and sustainability; housing and community services; and land and culture

- WHO recognition that urbanization is a major public health challenge in the twenty-first century and calls for a shared effort involving governments, international organizations, and business and civil society to put health at the heart of urban policy (Urban HEART: Urban Health Equity Assessment and Response Tool, 2010) and reduce urban health inequities (Hidden Cities: Unmasking and Overcoming Health Inequities in Urban Settings 2010)

- The Nine Principles of the City We Need articulated by the World Urban Campaign, a coalition of global partners of HABITAT to promote the outcomes document of Habitat III, the New Urban Agenda, and the work of HABITAT to 
promote well-planned, well-governed, and efficient cities and other human settlements, with adequate housing, infrastructure, and universal access to employment and basic services

- The updated Global Strategy for Women's, Children's and Adolescents' Health (WHO Partnership for Maternal, Newborn and Child Health) which will support the achievement of the women's, children's, and adolescents' health-related Sustainable Development Goals (SDGs) and which prioritizes gender equality the needs of marginalized and disadvantaged communities, including those living in urban and peri-urban settings, as key to achieving equitable progress in improving health outcomes. 